Joseph M. Unger and Carol M. Moinpour, SWOG Statistical Center, Fred Hutchinson Cancer Research Center; Judith A. Petersen, Fred Hutchinson Cancer Research Center; John J. Crowley, SWOG Statistical Center, Cancer Research and Biostatistics, Seattle, WA; Dawn L. Hershman, Columbia University Medical Center, New York NY; Kathy S. Albain, Loyola University Chicago Stritch School of Medicine, Maywood, IL; and Kenda Burg, NexCura, The Woodlands, TX

Published online ahead of print at www.jco.org on January 7, 2013

Supported in part by Grant No. CA037429 from the National Cancer Institute.

Presented at the 48th Annual Meeting of the American Society of Clinical Oncology, Chicago, IL, June 1-5, 2012; 18th Annual National Research Services Award Conference, Orlando, FL, June 23, 2012; and AcademyHealth Annual Research Meeting, Orlando, FL, June 23-26, 2012

Authors' disclosures of potential conflicts of interest and author contributions are found at the end of this article.

Corresponding author: Joseph M. Unger, MS, PhC, SWOG Statistical Center, Fred Hutchinson Cancer Research Center, M3-C102, 1100 Fairview Ave, Seattle, WA 98109; e-mail: junger@fhcrc.org.

(C) 2013 by American Society of Clinical Oncology

0732-183X/13/3105-536/\$20.00

DOI: $10.1200 / J C O .2012 .45 .4553$

\title{
Patient Income Level and Cancer Clinical Trial Participation
}

Joseph M. Unger, Dawn L. Hershman, Kathy S. Albain, Carol M. Moinpour, Judith A. Petersen, Kenda Burg, and John J. Crowley

\section{$\begin{array}{lllllllll}\text { A } & \text { B } & S & \mathbf{T} & \mathbf{R} & \mathbf{A} & \mathbf{C} & \mathbf{T}\end{array}$}

\section{Purpose}

Studies have shown an association between socioeconomic status (SES) and quality of oncology care, but less is known about the impact of patient SES on clinical trial participation.

\section{Patients and Methods}

We assessed clinical trial participation patterns according to important SES (income, education) and demographic factors in a large sample of patients surveyed via an Internet-based treatment decision tool. Logistic regression, conditioning on type of cancer, was used. Attitudes toward clinical trials were assessed using prespecified items about treatment, treatment tolerability, convenience, and cost.

\section{Results}

From 2007 to 2011, 5,499 patients were successfully surveyed. Forty percent discussed clinical trials with their physician, $45 \%$ of discussions led to physician offers of clinical trial participation, and $51 \%$ of offers led to clinical trial participation. The overall clinical trial participation rate was $9 \%$. In univariate models, older patients $(P=.002)$ and patients with lower income $(P=.001)$ and education $(P=.02)$ were less likely to participate in clinical trials. In a multivariable model, income remained a statistically significant predictor of clinical trial participation lodds ratio, 0.73; $95 \% \mathrm{Cl}$, 0.57 to $0.94 ; P=.01$ ). Even in patients age $\geq 65$ years, who have universal access to Medicare, lower income predicted lower trial participation. Cost concerns were much more evident among lower-income patients $(P<.001)$.

\section{Conclusion}

Lower-income patients were less likely to participate in clinical trials, even when considering age group. A better understanding of why income is a barrier may help identify ways to make clinical trials better available to all patients and would increase the generalizability of clinical trial results across all income levels.

\section{J Clin Oncol 31:536-542. (C) 2013 by American Society of Clinical Oncology}

\section{INTRODUCTION}

Clinical trials represent the final, critical step in evaluating the efficacy of new treatments for cancer. Continued access to and participation in cancer clinical trials are essential for reducing cancer mortality. However, only a small proportion of adult patients with cancer participate in clinical trials. ${ }^{1,2}$

The decision about what cancer treatment to undergo is complex and personal. Even if patients are eligible for a trial, they often refuse to participate. ${ }^{3,4}$ Patients express dislike of randomized treatment assignment and may already have a particular treatment in mind. ${ }^{4-7}$ Access factors (eg, transportation, cost), disease status, and physicians' attitudes toward patient participation are also important. $3,4,7,8$

The generalizability of clinical trial results depends on how representative the trial population is of the cancer population. For instance, comorbid conditions may discourage older patients from trial participation or may render patients clinically ineligible. ${ }^{9}$ In 1999, investigators at SWOG, a national clinical trials consortium, showed that older patients were substantially underrepresented in cancer trials. ${ }^{10}$ In 2000, Medicare changed its policy to cover the routine care costs of trial participation. A later SWOG study suggested that this policy change improved enrollment of older patients, but only for those with supplemental insurance to Medicare. ${ }^{11}$

Heightened awareness of socioeconomic (SES) disparities in access to medical, economic, or other resources is an important and current public policy issue and provided the motivation to investigate potential SES barriers to clinical trial participation, which might also inform the age disparity. Because patient-specific SES data are rarely collected for patients with cancer enrolled onto national clinical 
trials, this topic has not been previously well studied. ${ }^{12}$ In addition, participation in clinical trials is strongly influenced by the presence of comorbid illnesses; however, studies of clinical trial participation rarely include comorbidity data. ${ }^{12}$ Therefore, to address the research question, SWOG collaborated with a provider of online treatment decision tools to assess patterns of clinical trial participation according to patient-level SES and demographic variables, accounting for comorbid illnesses.

\section{PATIENTS AND METHODS}

\section{Administration}

Investigators from SWOG collaborated with NexCura (The Woodlands, TX), a provider of proprietary Internet-based cancer treatment decision tools. ${ }^{13}$ Patients were accessed through their registration to the NexCura treatment decision tool, which was embedded in multiple major canceroriented Web sites (eg, American Cancer Society). An e-mail was generated 3 months after each new registration (to allow patients time to make a treatment decision), offering the patient the opportunity to participate in the survey and providing a link to the survey Web site. The survey was completed online.

Patients were notified that information they provided would be reported in aggregate only. Because no individual identifiers were provided to researchers, the study was deemed institutional review board exempt.

\section{Eligibility}

To be eligible, patients had to be adults (age $\geq 18$ years) living in the United States. Patients must have been investigating treatment options for a first diagnosis of breast, colorectal, lung, or prostate cancer.

\section{Design}

All patients who agreed to participate were asked questions pertaining to their demographics, staging, and comorbid illnesses. Patients were asked whether they had made a treatment decision within the prior 3 months. Patients who answered no were asked to indicate why. These patients were then finished with the survey.

Patients who answered yes represented the evaluable patient cohort. These patients were asked whether they had discussed with their physician possible participation in a clinical trial. A brief description of a clinical trial was provided. Patients who answered either yes but were not offered a clinical trial, or no, were asked whether they thought clinical trials: (1) represented better treatment, (2) were more difficult to tolerate, (3) represented a gamble, (4) were inconvenient, and (5) were more difficult to pay for. These patients were then finished with the survey.

Patients who discussed a clinical trial with their physician and were offered trial participation were asked whether they participated in a clinical trial. Patients who answered yes were asked about their attitudes toward clinical trials (as noted in the previous paragraph) and were then finished with the survey. Patients who answered no were asked about their reasons for declining trial participation based on 24 prespecified questions from a prior study of barriers to clinical trial participation. ${ }^{7}$ These patients were then finished with the survey. The Data Supplement provides a full survey description.

\section{Statistical Considerations}

The primary objective was to assess, by SES and demographic factors: 1) rates of clinical trial enrollment, 2) patterns of enrollment onto trials, 3) attitudes toward clinical trials, and 4) reasons for nonparticipation in clinical trials. Conditional logistic regression was used to assess the association between SES or demographic variables and a given outcome, conditioning on cancer type. All evaluable patients of any stage were included. Multivariable logistic regression was used to assess multiple factors associated with clinical trial participation simultaneously.

\section{SES, Demographic, and Comorbidity Variables}

The demographic factors were: age ( $<65 v \geq 65$ years), sex, and race (African American $v$ white/other). Yearly household income was categorized as $<\$ 20,000$ versus $\$ 20,000$ to $\$ 34,999$ versus $\$ 35,000$ to $\$ 49,999$ versus
$\$ 50,000$ to $\$ 99,999$ versus $\geq \$ 100,000$ versus "don't know" versus "prefer not to answer." For the primary analysis, income was categorized as $<\$ 50,000$ versus $\geq \$ 50,000$ per year (the nearest approximation to the median), and education was categorized as $<2$-year versus $\geq 2$-year college degree. Binary indicator variables were used for consistency across factors and to aid interpretation. Additional analyses explored other binary categorizations of income. Income analyses were limited to patients with a reported income value.

A comorbidity score was derived from data on 18 comorbid conditions. ${ }^{14}$ Total travel distance to the clinic (a surrogate for convenience) was also obtained. Both factors were included as covariates in multivariable regression models, split at the median (comorbidity, zero to one $v \geq$ two; travel distance, $<13 v \geq 13$ miles). In addition, each multivariable model included the SES and demographic variables.

\section{RESULTS}

\section{Cohort Profile}

A total of 77,752 survey invitations were sent; 6,259 were returned, for a response rate of $8 \%$, approximately twice that of a prior survey using the NexCura treatment decision tool. ${ }^{13}$ Most patients $(5,499 ; 88 \%)$ had made a treatment decision in the prior 3 months, representing the evaluable patient cohort; responses by cancer type included 2,894 breast (53\%), 1,546 prostate (28\%), 651 lung (12\%), and 408 colorectal (7\%) cancers.

Twenty-two percent of patients were age $\geq 65$ years, $2.5 \%$ were African American, and 62\% were women (Table 1). In comparison, the US adult cancer population with a similar cancer distribution was estimated to be older ( $58 \%$ age $\geq 65$ years) and to have more African Americans (10\%) but the same proportion of women (62\%). ${ }^{11}$ There was good geographic representativeness compared with the US adult population (Fig 1). Survey participants were similar to nonparticipants with respect to sex (female, $62 \% v 63 \%$ ), income ( $>$ national median, 64\% v 63\%), and geographic region (Fig 1) but were more likely to have breast ( $52 \% v 42 \%)$ or prostate cancer $(28 \% v 20 \%)$ and less likely to have lung cancer (10\% v23\%).

Income was reported by $83 \%$ of patients, of whom $32 \%$ made $<\$ 50,000$ per year. Education level was obtained for all patients; $34 \%$ reported $<$ a 2-year college degree.

\section{Patterns of Decision Making}

Of the 5,499 evaluable patients, 2,174 (40\%) reported discussing clinical trial participation with their physician; among these, 978 (45\%) were offered a trial, and among these, 496 (51\%) participated in a clinical trial, and 482 (49\%) did not (Fig 2). There were statistically significant differences in the proportion of patients discussing trial participation in multivariable analysis by age $(42 \%<65$ years $v 29 \%$ $\geq 65$ years; $P<.001)$, income $(36 \%<\$ 50,000$ per year $v 42 \%$ $\geq \$ 50,000$ year; $P<.001)$, and education $(35 \%<2$-year college degree $v 42 \% \geq 2$-year college degree; $P<.001)$. Given clinical trial participation was discussed, African Americans were more likely (57\% v 45\%; $P=.03)$ and lower-income patients less likely (40\% v $47 \% ; P=.05)$ to be offered a clinical trial. No other statistically significant differences by SES or demographic factors were found (Data Supplement).

\section{Univariate Estimation of Clinical Trial Participation}

The overall rate of clinical trial participation among evaluable patients was $9.0 \%$ (496 of 5,499 patients; Fig 2). Conditioning on cancer type, clinical trial participation was less likely in older patients 


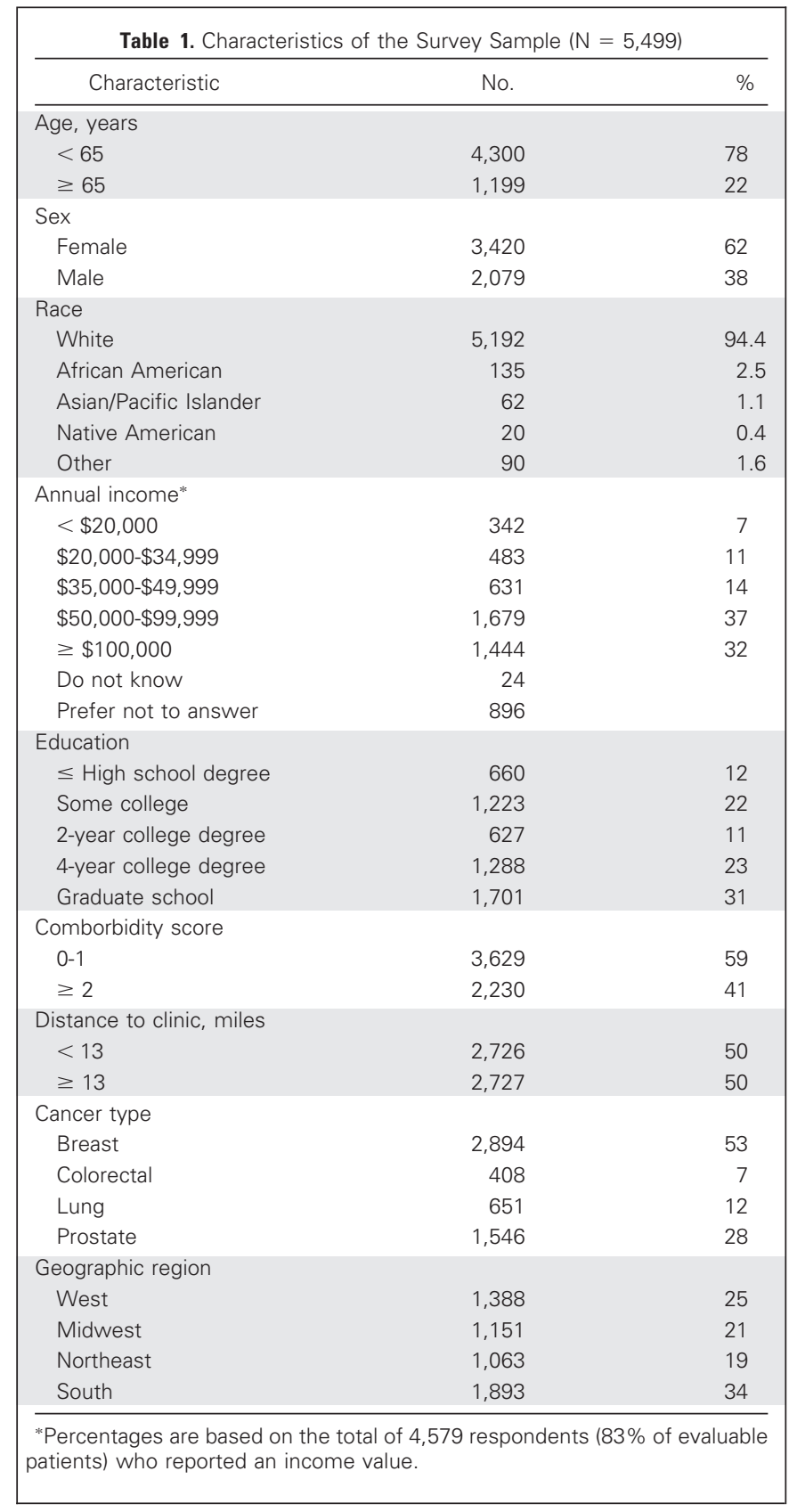

(5.4\% $v 10.0 \% ; P=.002)$ and patients with lower income $(7.6 \% v$ $10.0 \% ; P=.001)$ and lower education $(7.9 \% v 9.6 \% ; P=.02$; Table 2$)$. There were no statistically significant differences in trial participation by race or sex. Higher comorbidity scores and shorter distance to clinic were also associated with lower participation.

\section{Multivariable Estimation of Clinical Trial Participation}

In a multivariable conditional logistic regression model including all SES and demographic factors as well as the covariates comorbidity status and distance to clinic, income was the only SES or demographic factor that was statistically significantly associated with clinical trial participation (odds ratio $[\mathrm{OR}], 0.73 ; P=.01$; Table 2). Patients with lower income had lower clinical trial participation re-

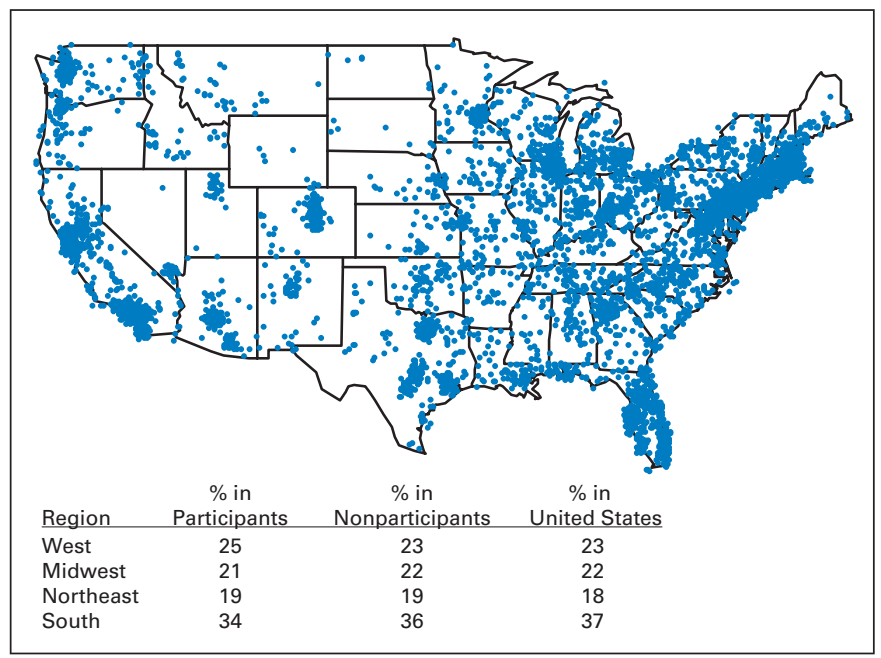

Fig 1. Geographic distribution of survey participants. The legend shows the proportion of survey participants by geographic region compared with proportions in nonparticipants and in the US adult population.

gardless of income cut point (Table 2). For instance, patients with income $<\$ 20,000$ per year showed $44 \%$ lower odds of participation.

\section{Association of Income and Clinical Trial Participation in Subcategories}

We explored the association of income with trial participation within subgroups of respondents using a forest plot (Fig 3). The odds of clinical trial participation were consistently lower in nearly all subcategories. Importantly, although there was a trend toward a stronger association of income with trial participation among those age $<65$ years (test for interaction of age and income, $P=.06$ ), income was associated with participation in older patients as well.

\section{Attitudes Toward Clinical Trials}

Patient attitudes toward clinical trials were similar for patients who did not discuss a trial $(\mathrm{n}=3,325)$ versus those who discussed but

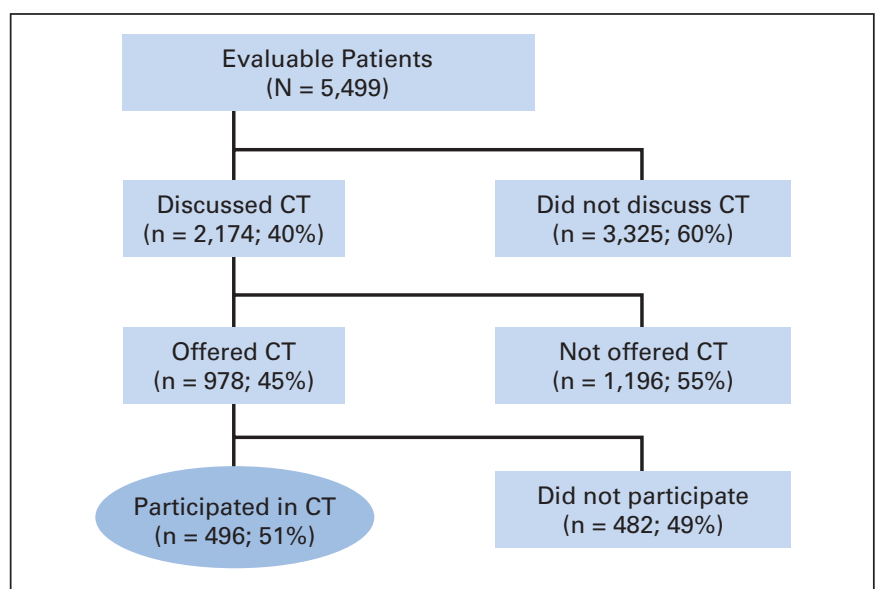

Fig 2. Patient flow diagram indicating decision-making patterns about clinical trial (CT) participation. A total of 77,752 survey invitations were sent, and 6,259 were returned; 760 respondents had not made a treatment decision within the 3 months since their initial registration on the NexCura Web site, leaving 5,499 evaluable patients. For the 760 respondents who had not made a treatment decision within the 3 months since their initial registration, most had made a treatment decision earlier than 3 months before $(65 \%)$ or were recently diagnosed but still undecided about treatment (15\%). 


\begin{tabular}{|c|c|c|c|c|}
\hline Factor & $\begin{array}{c}\text { Enrolled Onto } \\
\text { Clinical Trial (\%) }\end{array}$ & OR & $95 \% \mathrm{Cl}$ & $P$ \\
\hline \multicolumn{5}{|l|}{ Univariate model results } \\
\hline Age, years & & 0.64 & 0.48 to 0.85 & .002 \\
\hline$<65^{*}$ & 10.0 & & & \\
\hline$\geq 65 \dagger$ & 5.4 & & & \\
\hline Sex $\neq$ & & 0.97 & 0.63 to 1.48 & .88 \\
\hline Male* & 5.6 & & & \\
\hline Female & 11.1 & & & \\
\hline Race & & 1.26 & 0.73 to 2.19 & .40 \\
\hline White/other* & 9.0 & & & \\
\hline African Americant & 11.1 & & & \\
\hline Annual income & & 0.68 & 0.54 to 0.86 & .001 \\
\hline$\geq \$ 50,000^{*}$ & 10.0 & & & \\
\hline$<\$ 50,000 \dagger$ & 7.6 & & & \\
\hline Education & & 0.78 & 0.64 to 0.96 & .02 \\
\hline$\geq$ College $^{*}$ & 9.6 & & & \\
\hline$<$ Colleget & 7.9 & & & \\
\hline Comborbidity score & & 0.78 & 0.64 to 0.95 & .01 \\
\hline $0-1^{*}$ & 10.1 & & & \\
\hline$\geq 2 \dagger$ & 7.5 & & & \\
\hline Distance to clinic, miles & & 0.66 & 0.55 to 0.80 & $<.001$ \\
\hline$\geq 13^{*}$ & 10.5 & & & \\
\hline$<13 t$ & 7.6 & & & \\
\hline \multicolumn{5}{|l|}{ Multivariable model results } \\
\hline Age & & 0.79 & 0.58 to 1.08 & .14 \\
\hline Sex & & 0.93 & 0.58 to 1.49 & .75 \\
\hline Race & & 1.31 & 0.74 to 2.33 & .35 \\
\hline Income & & 0.73 & 0.57 to 0.94 & .01 \\
\hline Education & & 0.92 & 0.73 to 1.16 & .49 \\
\hline Comorbidity score & & 0.81 & 0.65 to 1.02 & .07 \\
\hline Distance to clinic & & 0.66 & 0.54 to 0.81 & $<.001$ \\
\hline \multicolumn{5}{|l|}{$\begin{array}{l}\text { Multivariable model results } \\
\text { for different annual } \\
\text { income cut points }\end{array}$} \\
\hline$\$ 20,000$ & & 0.56 & 0.35 to 0.91 & .02 \\
\hline$\$ 35,000$ & & 0.73 & 0.54 to 0.98 & .04 \\
\hline$\$ 50,000$ & & 0.73 & 0.57 to 0.94 & .01 \\
\hline$\$ 100,000$ & & 0.79 & 0.63 to 0.98 & .04 \\
\hline \multicolumn{5}{|c|}{$\begin{array}{l}\text { Abbreviation: OR, odds ratio. } \\
{ }^{*} \text { Coded as } 1 . \\
\text { tCoded as } 0 \text {. } \\
\text { ¥Although the observed participation rate for women was almost twice that } \\
\text { for men ( } 11.1 \% \vee 5.6 \%) \text {, the difference was not statistically significant after } \\
\text { conditioning on cancer type because of the relatively high rate of enrollment } \\
\text { among patients with breast cancer. In non-sex-specific diseases only (lung } \\
\text { and colorectal cancers), the rates were } 8.4 \% \text { for men and } 8.0 \% \text { for women. }\end{array}$} \\
\hline
\end{tabular}

were not offered a trial ( $\mathrm{n}=1,196$; data not shown). These subsets were combined. Concern about how to pay for clinical trial participation was higher in lower-income patients (OR, 1.79; 95\% CI, 1.53 to $2.10 ; P<.001)$ and lower-education patients (OR, 1.50; 95\% CI, 1.29 to $1.75 ; P<.001)$ but was lower in older patients (OR, $0.54 ; 95 \% \mathrm{CI}$, 0.44 to $0.65 ; P<.001)$, likely because of Medicare access. Rates of concern about how to pay for trial participation were $53 \%$ for those with income $<\$ 20,000,46 \%$ for income from $\$ 20,000$ to $\$ 34,999$, $43 \%$ for income from $\$ 35,000$ to $\$ 49,999,36 \%$ for income from $\$ 50,000$ to $\$ 99,999$, and $24 \%$ for income $\geq \$ 100,000$, indicating an inverse linear relationship $(P<.001)$.

Among patients who participated in a clinical trial $(n=496)$, older patients were more likely to consider trial participation a gamble
(OR, 2.51; 95\% CI, 1.28 to $4.93 ; P=.008$ ), lower-education patients were less likely to think a clinical trial involved extra inconvenience (OR, $0.56 ; 95 \% \mathrm{CI}, 0.35$ to $0.88 ; P=.01$ ), and women $(\mathrm{OR}, 4.02 ; 95 \%$ CI, 1.26 to $12.82 ; P=.02$ ) and lower-income patients (OR, 2.63; 95\% CI, 1.53 to $4.51 ; P<.001)$ were more likely to worry about how clinical trial participation would be paid for. A strong linear association between income level and concern about how to pay for clinical trial participation was also evident in patients who participated in a clinical trial $(P<.001$; rates not shown).

\section{Reasons for Nonparticipation in Clinical Trials}

Among those patients who were offered a clinical trial but declined ( $\mathrm{n}=482)$, treatment-related concerns, especially dislike of randomized treatment (68\%), were the most frequently cited reasons for nonparticipation (Fig 4). Each of the 24 questions in Figure 4 was analyzed in multivariable regression. Lower income was strongly associated with more concern about how to pay for clinical trial treatment $(P=.01)$ and less concern that a research protocol would determine choice of treatment $(P=.01)$. Other differences are shown in Figure 4. A strong linear association between income level and concern about how to pay for clinical trial participation was also evident in patients who were offered a clinical trial but declined $(P<.001$; rates not shown).

\section{DISCUSSION}

In this large national survey, patients with lower income were less likely to participate in a clinical trial, even accounting for comorbidity and education. Simultaneously, lower-income patients were more likely than higher-income patients to report concern about how to pay for clinical trial participation.

Proportional minority and female enrollment onto cancer clinical trials and inadequate older patient enrollment have been observed in many studies. ${ }^{6,10,11,15-17}$ Although distance to clinic has been cited as a reason for nonparticipation in clinical trials, in this study, trial participation was higher among patients who traveled a greater distance. ${ }^{4}$ This may be the result of the willingness of patients seeking trials to travel farther. Such patients may also be healthier, which could partly explain why travel distance has been found to be positively associated with improved survival in clinical trials, even after accounting for cancer stage and performance status. ${ }^{18}$

Few studies have evaluated the association between income and clinical trial enrollment. Instead, some studies have used area-level surrogates for SES variables through census data. ${ }^{19-21}$ The associations found in these studies were sometimes not retained in multivariable modeling, perhaps because of a lack of patient-level data and corresponding loss of power. ${ }^{20,21}$ A large study using a telephone survey to assess clinical trial recruitment patterns found that middle-income individuals ( $\$ 15,000$ to $\$ 50,000$ per year) were less likely to participate. ${ }^{22}$ However, this study was limited to Maryland only, was not cancer specific, and did not collect comorbidity data. Some studies have found associations of lower SES with surrogate outcomes for trial participation, such as willingness to participate in or awareness of clinical trials. ${ }^{23,24}$ Other studies have found no SES association with trial participation, although these studies had small sample sizes ${ }^{25,26}$ and high levels of missingness for SES factors. ${ }^{27}$ In contrast, our study 


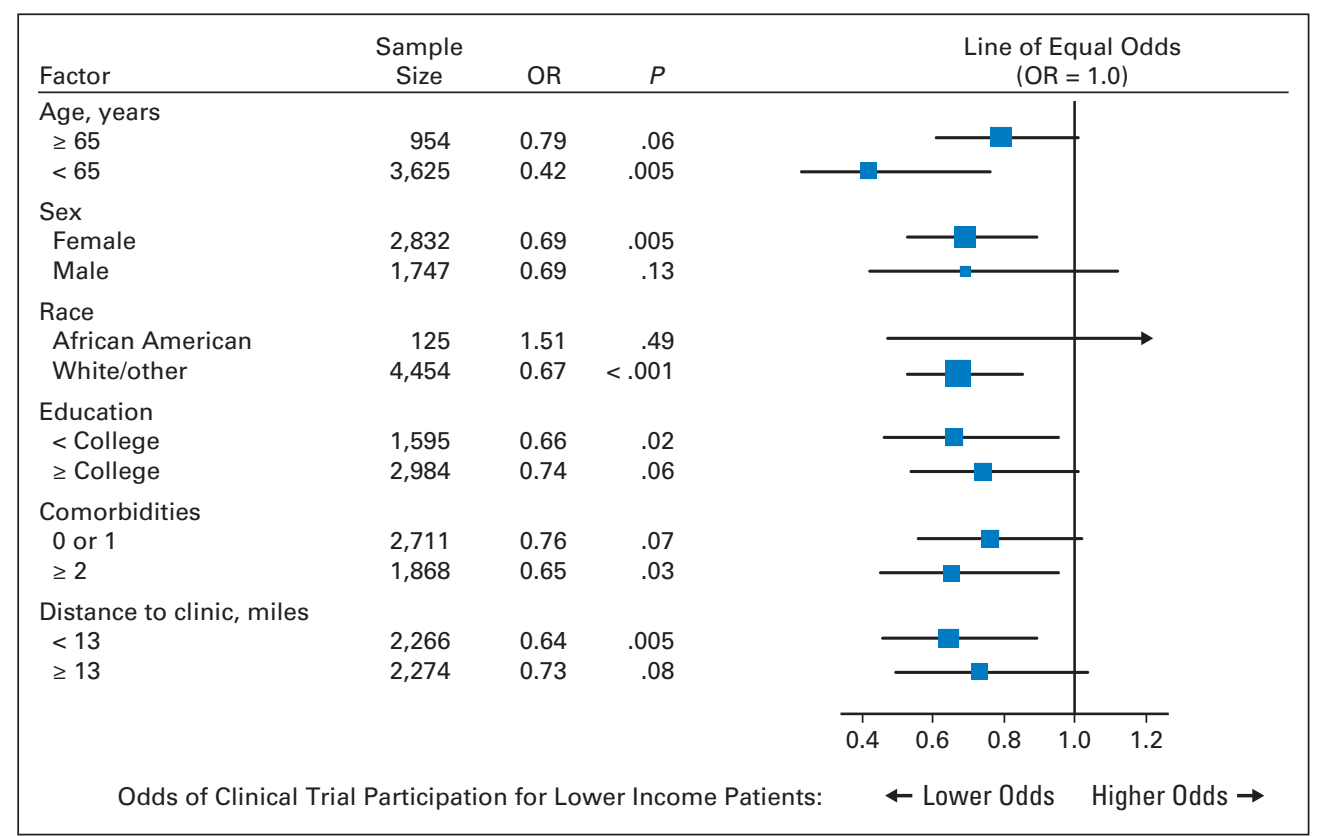

Fig 3. Forest plot of the association of income and clinical trial participation by each study factor. Each square represents an odds ratio (OR), and each horizontal line is the $95 \% \mathrm{Cl}$. The vertical line is the line of equal odds. For lower-income individuals, the odds of clinical trial participation were consistently lower (that is, to the left of the line of equal odds) within nearly all subgroups of all the factors included in this analysis, indicating that the association between income and participation was independent of subgroup membership. had patient-level SES data, assessed clinical trial enrollment (by patient report) rather than willingness to participate in or awareness of clinical trials, and had a large number of patients.

One explanation for our study results might be that higherincome individuals are better insured. Although insurance status was not collected in this survey, we observed that lower income predicted lower clinical trial participation in patients age $\geq 65$ years, indicating an income disparity even in a population with universal access to Medicare. We also found no evidence that the association of lower income with trial enrollment differed between states with and without insurance mandates for coverage of clinical trials (interaction $P=.32$ ). Finally, lower income may be a selection factor for hospitals that are less likely to offer clinical trial participation. However, we observed that lower-income patients were less likely to be offered a trial given a trial was discussed, suggesting an income disparity even when a clinical trial was explicitly under consideration.

This study also provides strong evidence that lower-income patients are more likely than higher-income patients to be concerned about how to pay for clinical trial participation. However, the National Cancer Institute, in summarizing the literature, has stated that

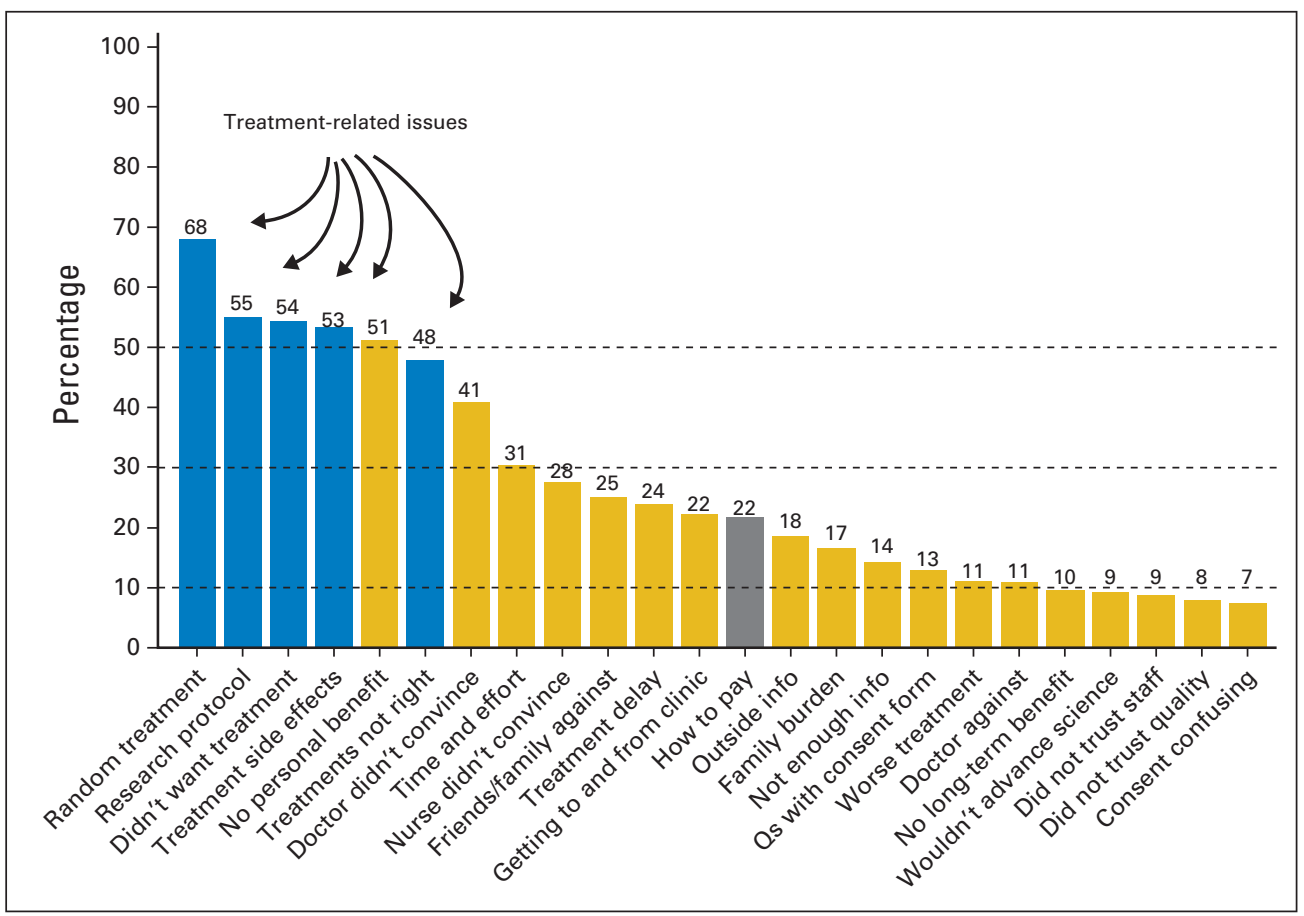

Fig 4. Reasons for declining to participate in clinical trials. Among patients who were offered a clinical trial but did not participate $(n=$ 482), the most common reasons cited for nonparticipation were treatment-related concerns (ie, fear of random assignment, did not want the specified protocol treatment, and so on). Other reasons that differed by socioeconomic or demographic factors included the following: age: older patients were less concerned about travel related to clinical trial participation $(P=.02)$, less concerned about how to pay for clinical trial participation $(P=.04)$, and less concerned about time and effort related to clinical trial participation $(P=.04)$; sex: women were less likely to have family and friends opposed to their clinical trial participation $(P=.03)$; income: lower-income patients were more concerned about how to pay for clinical trial participation $(P=.01)$, less concerned that a research protocol would determine their treatment choice $(P=.01)$, less likely to have family or friends opposed to their clinical trial participation $(P=.03)$, and less concerned about random treatment assignment in a clinical trial $(P=.04)$; and education: lower-education patients were less concerned about clinical trial adverse effects $(P=.05)$. 
"patient care costs for clinical trials are not appreciably higher than costs for patients not enrolled in trials." 28 The National Cancer Institute cites in particular the Costs of Cancer Treatment study by Goldman et $\mathrm{al}^{29}$ at RAND, which found an overall small, nonstatistically significant increase $(6.5 \%)$ in trial versus nontrial costs and no increase in prescription out-of-pocket costs. ${ }^{30}$ Other studies have found similar results. ${ }^{31-34}$

One limitation of this study was the inability to assess concerns about cancer treatment costs in general. But even if treatment cost concerns are a general issue, public policy changes could reduce these concerns in the clinical trial setting specifically, with the potential to reduce the disparity in trial participation rates. One approach would be to cover excess costs for trial participation for all patients. Prior evidence suggests that even in an insured population, copays and coinsurance may deter clinical trial participation. ${ }^{11}$ Similarly, payment to individuals to encourage clinical trial participation has been explored. ${ }^{35-37}$ Such approaches would require careful calibration of the size of any monetary incentive attached to an offer of trial participation $^{38}$ to avoid undue influence, as indicated in the US Common Rule for the Protection of Human Subjects. A different strategy could be direct-to-consumer advertising (DTCA) targeted to lower-income populations. DTCA has increased in recent years, and awareness of oncology-related DTCA is generally high among patients with cancer $(>80 \%) .{ }^{39,40}$ Finally, lower-income patients may be more sensitive to indirect costs, such as having to take time off work for extra clinic visits. Certain low-cost considerations for patients related to time, convenience, or transportation, such as parking passes or bus fare, could improve participation among lower-income patients in particular. ${ }^{41}$ Interventions to provide more-comprehensive information to patients about costs and benefits associated with clinical trial participation could also be useful. Jacobsen et $\mathrm{al}^{42}$ recently reported that patients randomly assigned to receive printed educational materials plus a multimedia DVD intervention had more positive attitudes about clinical trials and more willingness to participate in trials than patients who received printed educational materials alone.

Patient self-report may limit the reliability of certain types of data (eg, comorbidity status). On the other hand, self-report is preferable for patient attitudes and SES variables. Also, although all $P$ values $\leq .05$ are reported, those cases where $0.01 \leq P \leq .05$ should be regarded with some suspicion because of the number of tests performed, whereas highly statistically significant $P$ values $(P \leq .01)$ are less likely to be significant by chance alone. Furthermore, inferences pertaining to African American patients were limited by the small proportion of African Americans in the survey. Finally, the survey was conducted among Web-based users to obtain a national sample of patients with patient-level SES data. Although the survey response rate was low, it was similar to rates reported in other Internet-based surveys. $^{13,43,44}$ The participant cohort was younger and less diverse than the general cancer population but was comparable to nonparticipants for several factors examined, including income. Nonetheless, the most important issue is the extent to which the inference about the association between income and clinical trial participation is generalizable beyond this Web-based cohort. ${ }^{45}$ Because income may be found to have a different impact on clinical trial participation in different populations, such as those without Internet access or nonrespondents, the validity of this finding requires confirmation in different study settings.

Improving participation of lower-income patients in clinical trials is important from multiple perspectives. Because clinical trials offer the newest cancer treatments, equal access to this important resource for patients of all income groups is essential. Also, improved lowerincome participation would allow clinical trials to be conducted more quickly and would better ensure the applicability of trial results to all income levels (ie, generalizability). Understanding that income is related to clinical trial participation could help guide policy decisions aimed at increasing access for lower-income patients.

\section{AUTHORS' DISCLOSURES OF POTENTIAL CONFLICTS OF INTEREST}

Although all authors completed the disclosure declaration, the following author(s) and/or an author's immediate family member(s) indicated a financial or other interest that is relevant to the subject matter under consideration in this article. Certain relationships marked with a " $U$ " are those for which no compensation was received; those relationships marked with a " $C$ " were compensated. For a detailed description of the disclosure categories, or for more information about ASCO's conflict of interest policy, please refer to the Author Disclosure Declaration and the Disclosures of Potential Conflicts of Interest section in Information for Contributors. Employment or Leadership Position: Kenda Burg, NexCura (C) Consultant or Advisory Role: None Stock Ownership: None Honoraria: None Research Funding: None Expert Testimony: None Other Remuneration: None

\section{AUTHOR CONTRIBUTIONS}

Conception and design: Joseph M. Unger, Kathy S. Albain, Carol M. Moinpour, Judith A. Petersen, John J. Crowley

Provision of study materials or patients: Judith A. Petersen

Collection and assembly of data: Joseph M. Unger, Judith A. Petersen, Kenda Burg

Data analysis and interpretation: Joseph M. Unger, Dawn L. Hershman, Kathy S. Albain, Carol M. Moinpour, Judith A. Petersen, John J. Crowley Manuscript writing: All authors

Final approval of manuscript: All authors

\section{REFERENCES}

1. Murthy VH, Krumholz HM, Gross CP: Participation in cancer clinical trials: Race-, sex-, and agebased disparities. JAMA 291:2720-2726, 2004

2. Tejeda HA, Green SB, Trimble EL, et al: Representation of African-Americans, Hispanics, and whites in National Cancer Institute cancer treatment trials. J Natl Cancer Inst 88:812-816, 1996

3. Comis RL, Miller JD, Aldigé CR, et al: Public attitudes toward participation in cancer clinical trials. J Clin Oncol 21:830-835, 2003
4. Lara PN Jr, Higdon R, Lim N, et al: Prospective evaluation of cancer clinical trial accrual patterns: Identifying potential barriers to enrollment. J Clin Oncol 19:1728-1733, 2001

5. Hunter CP, Frelick RW, Feldman AR, et al: Selection factors in clinical trials: Results from the Community Clinical Oncology Program Physician's Patient Log. Cancer Treat Rep 71:559-565, 1987

6. Klabunde CN, Springer BC, Butler B, et al: Factors influencing enrollment in clinical trials for cancer treatment. South Med J 92:1189-1193, 1999

7. Javid SH, Unger JM, Gralow JR, et al: A prospective analysis of the influence of older age on physician and patient decision-making when considering enrollment to breast cancer clinical trials (SWOG S0316). Oncologist 17:1180-1190, 2012

8. Ross S, Grant A, Counsell C, et al: Barriers to participation in randomised controlled trials: A systematic review. J Clin Epidemiol 52:1143-1156, 1999

9. Bergman L, Dekker G, van Kerhoff EH, et al: Influence of age and comorbidity on treatment choice and survival in elderly patients with breast cancer. Breast Cancer Res Treat 18:189-198, 1991

10. Hutchins LF, Unger JM, Crowley JJ, et al: Underrepresentation of patients 65 years of age or 
older in cancer-treatment trials. N Engl J Med 341 : 2061-2067, 1999

11. Unger JM, Coltman CA Jr, Crowley JJ, et al: Impact of the year 2000 Medicare policy change on older patient enrollment to cancer clinical trials. J Clin Oncol 24:141-144, 2006

12. Ford JG, Howerton MW, Lai GY, et al: Barriers to recruiting underrepresented populations to cancer clinical trials: A systematic review. Cancer 112: 228-242, 2008

13. Markman $M$, Luce R: Impact of the cost of cancer treatment: An Internet-based survey. J Oncol Pract 6:69-73, 2010

14. Katz JN, Chang LC, Sangha O, et al: Can comorbidity be measured by questionnaire rather than medical record review? Med Care 34:73-84 1996

15. Trimble EL, Carter CL, Cain D, et al: Representation of older patients in cancer treatment trials. Cancer 74:2208-2214, 1994 (suppl)

16. Lewis JH, Kilgore ML, Goldman DP, et al: Participation of patients 65 years of age or older in cancer clinical trials. J Clin Oncol 21:1383-1389, 2003

17. Talarico L, Chen G, Pazdur R: Enrollment of elderly patients in clinical trials for cancer drug registration: A 7-year experience by the US Food and Drug Administration. J Clin Oncol 22:46264631, 2004

18. Lamont EB, Hayreh $D$, Pickett $K E$, et al: Is patient travel distance associated with survival on phase II clinical trials in oncology? J Natl Cancer Inst 95:1370-1375, 2003

19. Gross CP, Filardo G, Mayne ST, et al: The impact of socioeconomic status and race on tria participation for older women with breast cancer. Cancer 103:483-491, 2005

20. Du W, Gadgeel SM, Simon MS: Predictors of enrollment in lung cancer clinical trials. Cancer 106: 420-425, 2006

21. Sateren WB, Trimble EL, Abrams J, et al: How sociodemographics, presence of oncology specialists, and hospital cancer programs affect accrual to cancer treatment trials. J Clin Oncol 20:2109-2117 2002

22. Baquet $C R$, Commiskey $P$, Daniel Mullins $C$ et al: Recruitment and participation in clinical trials: Socio-demographic, rural/urban, and health care access predictors. Cancer Detect Prev 30:24-33, 2006

23. Brown DR, Topcu M: Willingness to participate in clinical treatment research among older African Americans and whites. Gerontologist 43:6272,2003

24. Lara PN Jr, Paterniti DA, Chiechi $C$, et al: Evaluation of factors affecting awareness of and willingness to participate in cancer clinical trials. J Clin Oncol 23:9282-9289, 2005

25. Avis NE, Smith $\mathrm{KW}$, Link $\mathrm{CL}$, et al: Factors associated with participation in breast cancer treatment clinical trials. J Clin Oncol 24:1860-1867, 2006

26. Kemeny $M M$, Peterson $B L$, Kornblith $A B$, et al: Barriers to clinical trial participation by older women with breast cancer. J Clin Oncol 21:22682275, 2003

27. Chang SM, Barker FG 2nd, Schmidt MH, et al: Clinical trial participation among patients enrolled in the Glioma Outcomes Project. Cancer 94:26812687, 2002

28. National Cancer Institute: Conducting clinical trials. http://mww.cancer.gov/clinicaltrials/conducting/cost

29. Goldman DP, Berry SH, McCabe MS, et al: Incremental treatment costs in national cancer institute-sponsored clinical trials. JAMA 289:29702977, 2003

30. Kilgore ML, Goldman DP: Drug costs and out-of-pocket spending in cancer clinical trials. Contemp Clin Trials 29:1-8, 2008

31. Barlow W, Taplin S, Seger D, et al: Medical care costs of cancer patients on protocol. Presented at a National Cancer Institute meeting, Bethesda, MD, July 7, 1998

32. Bennett CL, Stinson TJ, Vogel V, et al: Evaluating the financial impact of clinical trials in oncology: Results from a pilot study from the association of American Cancer Institutes/Northwestern University Clinical Trials Costs and Charges Project. J Clin Oncol 18:2805-2810, 2000
33. Fireman $\mathrm{BH}$, Fehrenbacher $\mathrm{L}$, Gruskin EP, et al: Cost of care for patients in clinical trials. J Natl Cancer Inst 92:136-142, 2000

34. Wagner JL, Alberts SR, Sloan JA, et al: Incremental costs of enrolling cancer patients in clinical trials: A population-based study. J Natl Cancer Inst 91:847-853, 1999

35. Macklin R: On paying money to research subjects: "Due" and "undue" inducements. IRB 3:1-6, 1981

36. McNeill P: Paying people to participate in research: Why not? A response to Wilkinson and Moore. Bioethics 11:390-396, 1997

37. Wilkinson $M$, Moore $A$ : Inducement in research. Bioethics 11:373-389, 1997

38. Viens AM: Socio-economic status and inducement to participate. Am J Bioeth 1:1f-2f, 2001

39. Donohue JM, Cevasco M, Rosenthal MB: A decade of direct-to-consumer advertising of prescription drugs. N Engl J Med 357:673-681, 2007

40. Abel GA, Burstein HJ, Hevelone ND, et al: Cancerrelated direct-to-consumer advertising: Awareness, perceptions, and reported impact among patients undergoing active cancer treatment. J Clin Oncol 27:41824187, 2009

41. McCabe MS, Varricchio CG, Padberg RM: Efforts to recruit the economically disadvantaged to national clinical trials. Semin Oncol Nurs 10:123-129, 1994

42. Jacobsen PB, Wells KJ, Meade $C D$, et al: Effects of a brief multimedia psychoeducational intervention on the attitudes and interest of patients with cancer regarding clinical trial participation: A multicenter randomized controlled trial. J Clin Oncol 30:2516-2521, 2012

43. Hollowell CM, Patel RV, Bales GT, et al: Internet and postal survey of endourologic practice patterns among American urologists. J Urol 163: 1779-1782, 2000

44. Kim HL, Gerber GS, Patel RV, et al: Practice patterns in the treatment of female urinary incontinence: A postal and internet survey. Urology 57:4548, 2001

45. Krosnick JA: Survey research. Annu Rev Psychol 50:537-567, 1999 